\title{
Mastite por Paracoccidioidomicose: Relato de Caso
}

\author{
Mastitis due to Paracoccidioidomycosis: a Case Report
}

Antônio Chambô Filho, Fabio Leal Laignier Borges, Luiz Cálice Cintra, Rubia Mara Martins

\section{RESUMO}

A paracoccidioidomicose é uma importante micose sistêmica, endêmica na América Latina. A infecção é usualmente adquirida por inalação das particulas do micélio. Na sua maioria são infecções assintomáticas e estão associadas a vários fatores do hospedeiro, como sexo, idade, fatores genéticos, bem como às características do agente infeccioso e sua virulência. Apresentamos um caso de mastite por paracoccidioidomicose, com o objetivo de demonstrar que pacientes idosas e com abcessos na mama devem ser submetidas à biópsia.

PALAVRAS-CHAVE: Paracoccidioidomicose. Paracoccidioides brasiliensis. Mama: doença benigna. Mama: infecções.

\section{Introdução}

A paracoccidioidomicose, blastomicose sulamericana ou doença de Lutz-SplendoreAlmeida é a infecção fúngica sistêmica de maior prevalência na América Latina, atingindo de forma endêmica principalmente o Brasil, com a maioria dos casos, Venezuela e Colômbia. Acredita-se que a incidência da doença se situe entre um a três por 100.000 habitantes nessa área ${ }^{1,2}$.

O seu agente etiológico é o Paracoccidioides brasiliensis, um fungo assexuado e dimórfico, que se desenvolve como levedura no meio de cultura a $37^{\circ} \mathrm{C}$ e na forma de micélio filamentoso em temperaturas entre $4^{\circ}$ e $28^{\circ} \mathrm{C}$. Nos tecidos infectados e nas secreções e pus das lesões são encontradas leveduras arredondadas, cuja parede celular é espessa e refringente, mostrandose isoladas ou em pequenos grupos de células.

A paracoccidioidomicose tem sido observada em todas as faixas etárias, com acentuada predominância entre os 30 e 50 anos de idade. Até a puberdade, a incidência da moléstia é igual para ambos os sexos, contudo na vida adulta $80 \%$ dos pacientes são do sexo masculino. Explicase o fato pela proteção dada pelos estrógenos à mulher adulta ${ }^{3,4}$.

Departamento de Tocoginecologia da Escola de Medicina da Santa Casa de Misericórdia de Vitória - ES (EMSCAM)

Correspondência:

Antônio Chambô Filho

Rua Constante Sodré, $\mathrm{n}^{\circ} 1027$ - Praia do Canto

29055-420 - Vitória - ES
Entre os fatores comportamentais, o trabalho com o solo e vegetais em área rural é fator predisponente importante, visto que nesta população a porcentagem de indivíduos assintomáticos com teste positivo pode alcançar até $60 \%$. Descobertas casuais do $P$. brasiliensis em necrópsias de individuos falecidos por outras causas revelam a possibilidade de a infecção ocorrer de modo assintomático ou subclínico durante toda a vida ${ }^{5}$. O agente esporadicamente se comporta como oportunista, causando doença em pacientes imunossuprimidos, com neoplasias ou submetidos à transplante renal, ou naqueles com síndrome da imunodeficiência adquirida.

A porta de entrada do Paracoccidioides brasiliensis é o trato respiratório, sendo portanto o pulmão o órgão primariamente lesado nesta infecção. Excepcionalmente, este patógeno provoca lesões primárias, por inoculação traumática, no tegumento cutâneo ou mucoso. Mais freqüentemente a pele é alcançada pelo fungo por disseminação hematogênica ou por contigüidade a partir de lesões mucosas ou ganglionares.

A forma mais típica de reação inflamatória à presença do $P$. brasiliensis é o granuloma epitelióide, que se forma em torno das leveduras e é constituído por células gigantes e células epitelióides. Na área central do granuloma podese observar presença de supuração e necrose de coagulação ${ }^{6}$.

Múltiplos órgãos são envolvidos no curso desta micose sistêmica: pulmões, tegumento cutâneo e mucoso, linfonodos, supra-renais, sis- 
tema nervoso central, figado, baço, intestinos, olhos, ossos, pâncreas, ovários, testículos, útero, peritônio, tiróide, etc., podendo eventualmente simular neoplasia.

As lesões podem estar em qualquer parte do corpo, podendo ser únicas ou múltiplas; o polimorfismo é sua característica, variando de cor, tamanho e aspecto. Podem se apresentar como pápulas ou nódulos, ulcerados, abscessos, vegetações ou lesões verrucosas.

A paracoccidioidomicose pode se apresentar associada a outras doenças como a tuberculose, hanseníase, doença de Hodgkin, carcinoma de pulmão e paratiróide, esporotricose, cromoblastomicose, candidiase, histoplasmose, criptococose, doença de Chagas, lues, esquistossomose mansônica, poliartrite nodosa e síndrome da imunodeficiência adquirida ${ }^{7}$.

O estudo foi proposto com o objetivo de alertar para a importância da biópsia nas lesões mamárias recidivantes e em pacientes idosas.

\section{Relato do caso}

A.M.J, 72 anos, admitida no Serviço de Pósgraduação de Ginecologia e Obstetrícia da Santa Casa de Misericórdia de Vitória no dia 02/05/ 97 apresentando abscesso de $4 \mathrm{~cm}$ de diâmetro no quadrante inferior externo da mama esquerda, com queixa de tosse não-produtiva de evolução crônica, com início após a realização de tratamento cirúrgico (histerectomia abdominal por miomatose uterina).

O exame clínico não demonstrou outras anormalidades senão o abscesso mamário. $\mathrm{O}$ exame radiológico pulmonar se encontrava normal, apesar da presença de pequena área de reabsorção óssea clavicular.

Foi submetida a drenagem com biópsia incisional, recebendo alta hospitalar para aguardar resultado do histopatológico. O resultado da biópsia demonstrou a presença de leveduras de fungo em células gigantes (Figuras 1 e 2).

Solicitou-se a presença da paciente na enfermaria de ginecologia, que compareceu após dez dias, apresentando lesões granulomatosas difusas na face (Figura 3), orelha e membros superiores.

O exame clínico demonstrou 3 nodulações submandibulares de $2 \mathrm{~cm}$ de diâmetro móveis e indolores e nodulação de $3 \mathrm{~cm}$ de diâmetro na fossa supraclavicular direita com a mesma característica anteriormente descrita.

Observava-se presença de lesão de $4 \mathrm{~cm}$ de diâmetro no quadrante inferior externo da mama esquerda (Figura 4), não-cicatrizada, drenando pequena quantidade de secreção purulenta, compativel com o local da biópsia.

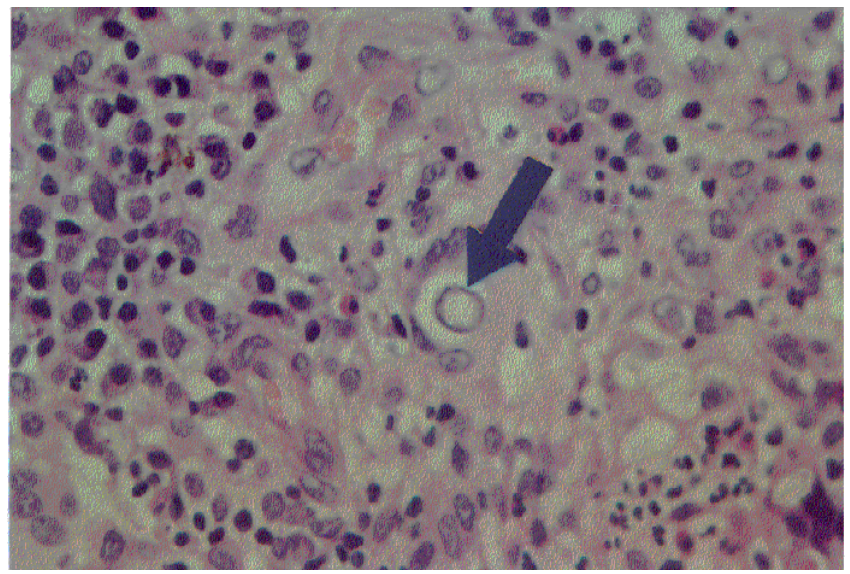

Figura 1 - Infiltrado leucocitário misto com microabscessos. Freqüentes estruturas de parasitos. No centro uma célula gigante com fungo. 400X-HE.

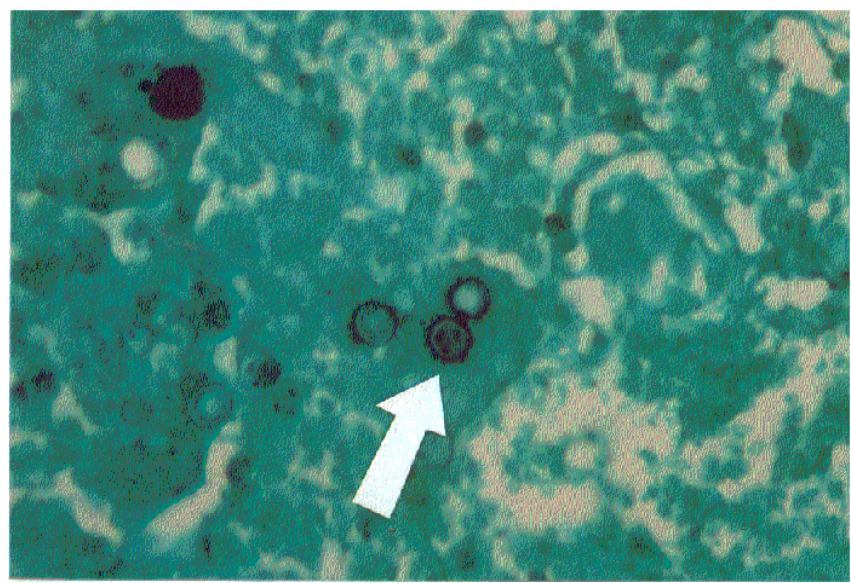

Figura 2 - Destacamos em escuro a presença de estruturas de fungo; aspecto em "roda de leme" do tipo observado em paracoccidioidomicose. 400X-Método de Grocott.

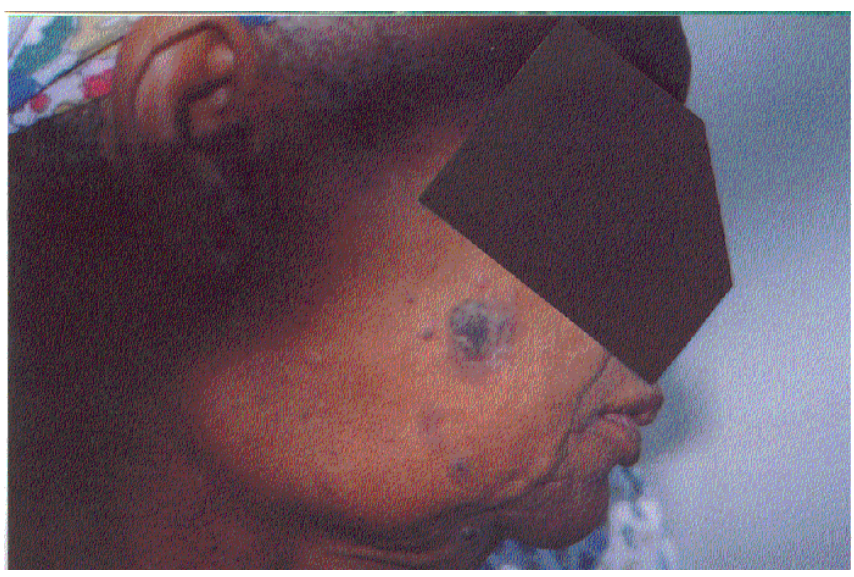

Figura 3-Lesões granulomatosas da face. 


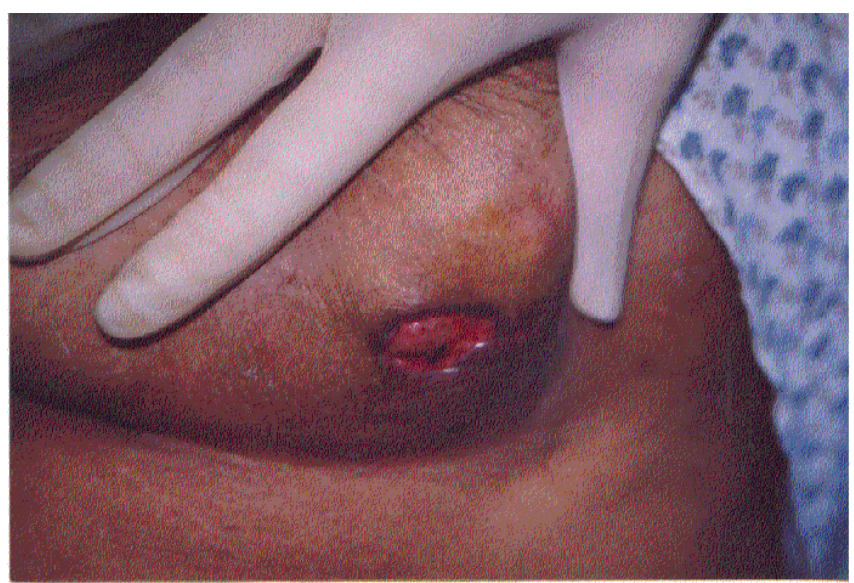

Figura 4 - Lesão mamária ulcerada de fundo limpo.

O exame clínico pulmonar e cardiológico mantinha-se sem alteração. O hemograma demonstrou leucocitose (20.500) com desvio à esquerda, $4 \%$ de bastões, $80 \%$ de segmentados e $14 \%$ de eosinófilos. As provas de coagulação, uréia e creatinina encontravam-se normais, bem como a radiografia de tórax de controle. A pesquisa de BAAR, ELISA para HIV e broncoscopia encontravam-se negativos. Iniciou-se a terapêutica com sulfadiazina-trimetoprim comprimidos (820/180 mg), via oral, de12/12 horas, mantida por 6 meses e reduzida à metade até completar 12 meses. Em seguida foi instituída terapia de manutenção com sulfadoxina, $500 \mathrm{mg}$ duas vezes por semana, até completar 2 anos de tratamento. A paciente apresentou remissão completa das lesões nos 2 primeiros meses de tratamento.

\section{Discussão}

As mastites são divididas classicamente em: puerperal e não-puerperal. O microorganismo mais freqüentemente encontrado é o Staphylococcus aureus e a participação de bacilos Gram-negativos e anaeróbios é restrita aos casos mais avançados, nos quais existe anóxia tecidual, sendo mais freqüente a presença destes nas mastites não-puerperais. Devido a essa associação de patógenos, principalmente nas formas purulentas, normalmente é inevitável a utilização de mais de um antimicrobiano. A mastite por paracoccidioidomicose é uma patologia infreqüente, com raros casos relatados na literatura $^{7,8}$, o que nos levou a refletir sobre a necessidade de uma melhor avaliação dos abscessos mamários, principalmente em pacientes idosas ou naquelas com abscessos freqüentes, nas quais, sem um estudo histopatológico, podemos estar lançando mão de um tratamento errôneo. Sendo a mastite queixa freqüente nos ambulatórios de ginecologia, devemos estar sempre atentos aos diagnósticos diferenciais, bem como ao sucesso terapêutico, à presença de lesão primária da mama envolvendo pele e subcutâneo com linfadenopatia e lesões cutâneas da face. O diagnóstico laboratorial pode ser realizado de três modos: demonstração microscópica do seu agente etiológico em exame a fresco, biópsia ou exame histopatológico (isolamento e identificação do fungo por meio do cultivo do material clínico) e por técnicas sorológicas.

O manejo terapêutico da paracoccidioidomicose deve obrigatoriamente compreender, além da ultilização de drogas antifúngicas (sulfamídicos, cetoconazol, itraconazol, anfotericina B), medidas que melhorem as condições gerais do paciente.

Os critérios de cura considerados aplicáveis são: os clínicos, com a regressão dos sinais e sintomas, cicatrização das lesões e involução da linfadenopatia, micológicos; negativação das culturas; radiológico: com estabilização do padrão de imagens, e imunológico, com negativação sorológica em amostras colhidas a cada três meses. E imprescindivel o acompanhamento pósterapêutico.

\section{SUMMARY}

Paracoccidioidomycosis is an important systemic endemic mycosis in Latin America. This infection is usually acquired via inhalation of mycelial particles. Most infected subjects develop an asymptomatic infection, which is associated with various host-related factors such as sex, age, genetic, as well as characteristics of the infecting agent, mainly its virulence. It is a systemic pathology. A case of mastitis due to paracoccidioidomycosis is presented with the objective to demonstrate that elderly patients with a breast abscess should be submitted to biopsy.

KEY WORDS: Paracoccidioidomycosis. Paracoccidioides brasiliensis. Breast: benign disease. Breast: infection.

\section{Referências}

1. Wanke B, Londero AT. Epidemiology and paracoccidioidomycosis infection . In: Franco M, Lacaz CS, Restrepo - Moreno A, Del Negro G, editors. Paracoccidioidomycosis. $1^{a}$ ed. Boca Ratton: CRC Press; 1994. p.109-20. 
2. Rodrigues MT, de Resende MA. Epidemiologic skin test survey of sensitivity to paracoccidioidin, histoplasmin and sporotrichin among gold mine workers of Morro Velho Mining, Brazil. Mycopathologia 1996; 135:89-98.

3. Restrepo A, Salazar ME, Cano LE. Estrogens inhibit mycelium to yeast transformation in the fungus Paracoccidioides brasiliensis: implications for resistence of females to paracoccidioidomycosis. Infect Immun 1984; 46:346-53.

4. Sano A, Nishimura K, Miyaji M. The Research Encouragement Award. Effects of sex hormones on sexual difference of experimental paracoccidioidomycosis. Nippon Ishinkin Gakkai Zasshi 1999; 40:1-8.

5. Angulo - Ortega A. Calcifications in paracoccidioidomycosis: are they the morphological manifestation of subclinical infections? PAHO Sci Publ 1972; 254: 129-3.

6. Iabuki K, Montenegro MR. Experimental paracoccidioidomycosis in the Syrian hamster: morphology, ultrastructure and correlation of lesions with presence of specific antigens and serum levels of antibodies. Mycopathologia 1979; 67:131-41.

7. Del Negro G. Outras lesões. Formas de ocorrência rara e associações com outros processos In: Del Negro G, Lacaz CS, Fiorillo AM, editores. Paracoccidioidomicose. $1^{\text {a }}$ ed. São Paulo: Sarvier/ Edusp; 1982. p.229-43.

8. Nohmi N, Gazinelli Sobrinho R. Paracoccidioidomicose de localização mamária. Rev Assoc Med Minas Gerais 1981; 32:41-2.

\section{“Colega,}

\section{No dia 30 de OUtubro É 0 dia do}

\section{médico Ginecologista e ObStetra.}

\section{Parabéns"}

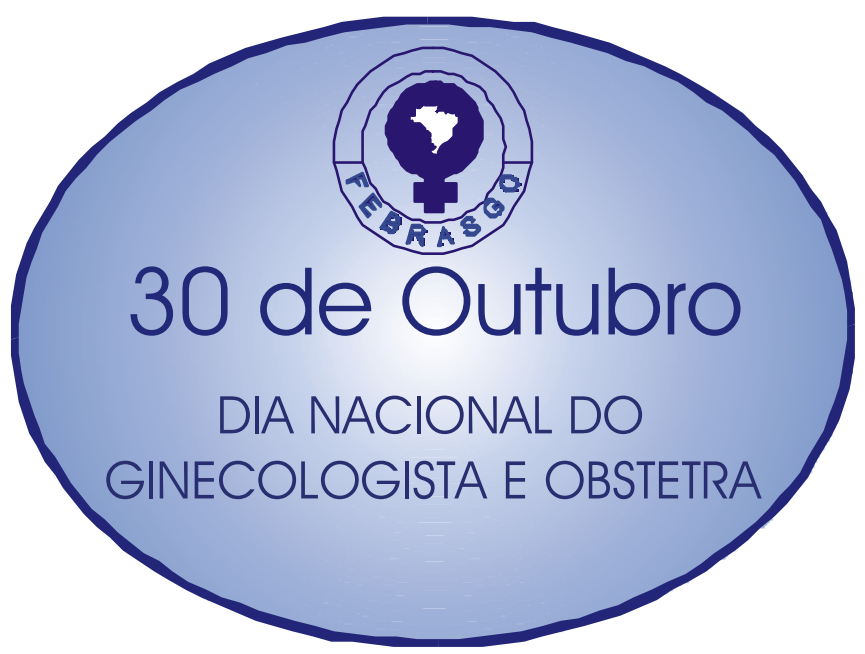

